\title{
Johann Mattheson e o ideal do Músico Perfeito
}

\author{
Johann Mattheson and the ideal of the Perfect Musician
}

\author{
Mônica Lucas \\ Universidade de São Paulo, São Paulo, São Paulo, Brasil \\ monicalucas@usp.br
}

Resumo: O Der Vollkommene Capellmeister ("O mestre-de-capela Perfeito") é o último escrito musical de Johann Mattheson (1671-1764) e, sem dúvida, sua obra mais ambiciosa. Ela representa o mais importante dos escritos pertencentes ao gênero de preceptivas musicais conhecidas como Musica Poetica - um conjunto de tratados surgidos entre os sécs. XVI e XVIII que faz uso sistemático de conceitos oriundos da instituição oratória para descrever os elementos da composição e da actio musical. Neste texto discorrer-se-á sobre a noção do músico-orador perfeito. Inicialmente, será examinada a maneira como Mattheson se representa em sua autobiografia, não como sujeito individual, mas como tipo cortesão humanista, cristão, luterano, propondo uma leitura da mesma a partir do universo poético-retórico. Nesta parte, será possível definir também o tipo constituído pelos destinatários da obra. Com isto, será possível evidenciar como o autor alemão emula lugares-comuns já apresentados em retóricas latinas, em especial o De Oratore ciceroniano e a Institutio Oratoria, de Quintiliano ao definir o mestre-de-capela perfeito. Finalmente, serão examinados lugares-comuns diretamente ligados à ideia do músico perfeito: a possibilidade de se atingir a perfeição, os requisitos para alcançá-la, assim como a contribuição da natureza e da arte para esta tarefa e a importância de conhecimentos extrínsecos à técnica musical para se atingir este ideal.

Palavras-chave: retórica musical em Johann Mattheson; ideal do músico perfeito; Musica Poetica no séc. XVIII.

Abstract: Der Vollkommene Capellmeister ("The perfect master of chapel") is Johann Mattheson's (1681-1767) last and most ambitious work. It is also the most important writing belonging to the genre of musical preceptives known as Musica Poetica, a group of treatises edited between the 16th and 18th centuries which make systematic import of concepts of the rhetoric tradition in order to describe musical elements. In this article, we concentrate on the notion of the perfect music-orator. First, we examine the 
manner by which Mattheson represents himself in his autobiography, not as an individual subject, but as a type - humanist, cortesan, christian, lutheran - suggesting a reading of this work from the poetic-rhetorical perspective. This allows us to also discuss the potential addressees of this work. This article also shows how Mattheson emulates commonplaces already presented in latin rhetoric handbooks, especially $D e$ Oratore, by Cicero, and Intitutio Oratoria, by Quintilian, when he discusses the perfect Kapellmeister. Finally, we will examine commonplaces directly connected to the idea of the Perfect Musician: the possibility to attain perfection and the requirements to accomplish it, as well as the contribution of nature and art and the importance of nonmusical knowledge to perform this task.

Keywords: Musical Rhetoric in Johann Mattheson; the ideal of the Perfect Musician; Musica Poetica in the 18th century.

Data de recebimento: $12 / 12 / 2015$

Data de aprovação final: 15/04/2016

\section{1 - Introdução}

Entregue para a impressão, como afirma Johann Matthesson, no dia 7 de julho de 1738, e vindo à luz em 1739, o Der Vollkommene Capellmeister - "O mestre-de-capela Perfeito" - é seu último escrito musical e, sem dúvida, sua maior obra. Ela constitui, ainda, o mais importante dos escritos pertencentes ao gênero de preceptivas musicais conhecidas como Musica Poetica - um conjunto de escritos dos sécs. XVI ao XVIII que faz uso sistemático de elementos oriundos da instituição oratória para descrever os elementos da composição e da actio musical.

Este texto concentrar-se-á na noção retórica do músico-orador perfeito apresentada por Mattheson em sua importante obra, mostrando como ele emula autoridades antigas. Para isto, inicialmente, será examinada a maneira como Mattheson se representa em sua autobiografia, não como sujeito, mas como tipo cortesão humanista, cristão, luterano, propondo uma leitura da mesma a partir do gênero literário que a retórica conhece como vida. Esta leitura permitirá supor também o tipo constituído pelos destinatários da obra - o cortesão igualmente erudito e engenhoso. 
A seguir, discutirei alguns dos lugares-comuns já apresentados em retóricas latinas e também usados por Mattheson para constituir o ideal do mestre-de-capela perfeito. Serão examinados lugares-comuns diretamente ligados à ideia do músico perfeito: a possibilidade de se atingir a perfeição, os requisitos para alcançá-la, assim como a contribuição da natureza e da arte para esta tarefa e a importância de conhecimentos extrínsecos à técnica musical para se atingir este ideal.

\section{Johann Mattheson segundo o "Fundamento para um Arco Triunfal"}

A principal fonte de informação a respeito do compositor Johann Mattheson (16811764) é sua autobiografia, incluída em "Fundamento para um arco triunfal, em que as vidas, obras e méritos dos mais virtuosos mestres-de-capela, compositores, estudiosos musicais, artistas são apresentadas para maior edificação", ${ }^{1}$ por ele publicada em 1740. Trata-se de uma obra abrangente, que inclui vidas de 149 músicos, que ele conheceu em grande parte pessoalmente. Esta coleção de biografias está claramente inserida no gênero das vidas de personagens ilustres (Suetônio, Plutarco, Tácito, e, já no séc. XVI, as vidas de artistas publicadas por Vasari). Sendo assim, é obra dirigida a homens de letras, cujo conteúdo não deve ser lido subjetivamente, mas em chave retórica, como escrito de louvor ou vitupério. Nesta obra, Mattheson representa-se como um tipo cortesão e erudito. Nela, ele descreve sua educação e atuação musical, profissional, literária e filosófica, seu contato com poetas e seu trânsito pelos círculos letrados de Hamburgo.

Mattheson foi aluno da Gelehrtenschule des Johanneums, cuja história e reputação remontam à autoridade de Lutero (a instituição foi fundada por Johannes Bugenhagen, um dos colaboradores mais próximos e diretos do Reformador). É sabido que os ginásios luteranos foram grandes responsáveis pela difusão dos studia humanitatis no

\footnotetext{
${ }^{1}$ Grundlage einer Ehrenpforte, voran der tüchtigsten Capellmeister, Componisten, Musikgelehrten, Tonkünstler, u. Leben, Wercke, Verdienste, u. erscheinen sollen. Zum fernen Ausbau angegeben von Mattheson (Hamburg, 1740).
} 
mundo reformado². Esta orientação humanista fica clara em um olhar às ordenanças de ensino destes estabelecimentos, concentradas no estudo da gramática, da poesia e da retórica latina (e, em menor medida, grega). Nesta escola, Mattheson travou contato com autores latinos antigos, em especial Cícero, mas ainda Tácito, Plauto, Sêneca, e também modernos, sobretudo Erasmo, mas também Vossius e Petrus Ramus. ${ }^{3}$

É interessante notar que, na Ehrenpforte, Matthesson não faz nenhuma referência a seu mestre de música. Contudo, menciona dois importantes homens de letras que lá ensinaram: Paul Georg Krüsike e Johannes Schultze, ambos professores de poesia e retórica grega e latina na seconda e na prima, as classes mais avançadas. Desta forma, Mattheson, ao mesmo tempo que se representa como letrado, despreza a formação musical proporcionada pela antiga instituição da Musica Poetica, baseada na prática contrapontística. Em todos os seus escritos musicais, fica clara a defesa do estilo moderno, galante, melódico e baseado no baixo-contínuo.

Mattheson mostra ainda ser conhecedor das principais habilidades galantes, externas ao programa curricular dos ginásios luteranos: dança, desenho, cálculo, equitação, esgrima. Além das línguas estudadas na escola, Mattheson afirma ainda ter se dedicado ao aprendizado das línguas vulgares: italiano, francês e inglês. Ele menciona ainda o estudo da história, direito e política inglesas, além do direito, comércio e política internacionais. Mattheson assegura ter se exercitado "no estilo da corte", cumprindo o protocolo esperado na educação do galant-homme, tipo que menciona diversas vezes em seus escritos como sendo o destinatário de suas preceptivas musicais. As atividades ligadas ao exercício diplomático são comumente recomendadas pelos manuais humanistas de cortesania.

A despeito da publicação de diversos tratados musicais e da estreita ligação que manteve durante toda a vida com a arte dos sons, Mattheson não perseguiu a carreira

\footnotetext{
2 Para maiores informações sobre esta influência, cf. BARNES (2002), p.258-265.

3 Para maiores informações sobre a educação luterana, cf. LUCAS (2014) e VORBAUM (1863).
} 
de músico, mas a de adido diplomático. Ainda jovem, tornou-se preceptor (Hofmeister) de Cyrill Wich, filho do legado britânico em Hamburgo. Estes mestres particulares foram reconhecidamente importantes difusores dos studia humanitatis na Alemanha. ${ }^{4}$ De preceptor, passou à ocupação de secretário e escritor de cartas e documentos do pai de Cyrill, John Wich. Com a morte deste, Cyrill sucedeu o pai no cargo. Mattheson acompanhou-o por toda a vida, como secretário. Não há dúvida de que as tarefas de Mattheson nesta função necessariamente se valeram de conhecimentos retóricos, em especial da ars epistolaria (escrita de cartas), matéria integrante das preceptivas escolares. As cartas de Cícero constam como leituras obrigatórias nas ordenanças das escolas luteranas, tendo servido como modelo para os escritos do gênero epistolar.

Mattheson transitou por diversas academias literárias de Hamburgo, em que se cultivava a poesia alemã, além da latina e grega, emulando auctoritates antigas. Nelas, Mattheson travou contato com os poetas Heinrich Brockes, Johann Gottsched, Friedrich von Hagedorn e Friedrich Hunold (Menantes), autores importantes para a difusão de ideais humanistas, pela vertente francesa da galanterie, na Alemanha. 0 cultivo de poesia em latim e em vernáculo é central nos studia humanitatis. Autores humanistas tiveram uma reconhecida preocupação em valorizar e ampliar o vocabulário das línguas vulgares. Esta atenção também transparece também na obra literária de Mattheson, seja em suas próprias traduções, seja em suas críticas ao uso de estrangeirismos por autores como Gottsched ou Johann Scheibe, e em suas propostas de substituição destes termos pelos equivalentes alemães. ${ }^{5}$

Mattheson também foi editor e colaborador de revistas culturais, gênero literário surgido na Alemanha no início do séc. XVIII. O importante papel exercido pelas revistas na difusão de ideias humanistas para segmentos cada vez maiores da população tem

\footnotetext{
4 Para mais informações sobre este assunto, cf. BARNES (2002), p.374-377.

${ }^{5}$ Em um manuscrito de 8 páginas, de 1744, ele discute pormenorizadamente a tradução de Gottsched dos Entretiens sur la Pluralité des Mondes, 1686, de Fontenelle. Em Beyträge zur Kritischen Historie, comenta o Critischer Musikus, de Johann Scheibe. Em ambos os casos, propõe alternativas alemãs para a terminologia francófila empregada por estes autores.
} 
sido amplamente discutido e não necessita ser retomado neste artigo ${ }^{6}$. Mattheson foi editor da primeira revista musical alemã, Critica Musica (1722-1725), e colaborador ativo de diversas revistas germânicas dedicadas à filosofia, artes e história, como a Niedersächsische Nachrichten von Gelehrte Sachen ("notícias da baixa saxônia sobre assuntos eruditos").

Mattheson escreveu quatro importantes tratados musicais. Três foram publicados em sua juventude, num espaço de tempo de 8 anos, enquanto que o último e mais importante, foi publicado quase 20 anos após estes primeiros, em 1739.

Os três escritos orquestrais de juventude - Das neu-eröffnete Orchestre ("A orquestra recém-Inaugurada", 1713); Das beschützte Orchestre (“A orquestra amparada", 1717) e Das Forschende Orchestre ("A orquestra Investigativa", 1721)- são geralmente compreendidos como estudos preliminares a Der Vollkommene Capellmeister ("0 Mestre-de-Capela Perfeito", 1739), já que este último amplia e aprofunda as informações contidas nos escritos anteriores.

Embora não haja dúvida que as obras de Mattheson pertençam ao gênero de preceptivas musicais conhecido como musica poetica, o fato de elas não estarem escritas em latim (língua corrente destas preceptivas), e sim em alemão, indica que não se voltam, como a maior parte de suas congêneres, para o público escolar. Mattheson, em diversos pontos de seus tratados, indica seu destinatário como sendo o gallant homme.

Galante segundo o dicionário de Raphael Bluteau (1728, v.4 p.10) é um tipo cortesão, polido, naturalmente educado, que conhece os protocolos de circunstância, tempo e lugar da corte, sabendo sempre deleitar. No mundo germânico, o homem galante também aparece descrito, como por exemplo no discurso referencial de Christian Thomasius, proferido na Universidade de Leipzig em 1690. Em Hamburgo, autores que

\footnotetext{
${ }^{6}$ Para mais informações sobre o assunto, cf. MORROW (1997), p.1-18.
} 
transitaram pelos mesmos círculos sociais que aqueles frequentados por Mattheson, como Gottsched, Hagedorn e Hunold, também dirigem suas preceptivas, poesias e novelas ao público galante. Em Das Forschende Orchester ("a orquestra investigativa", 1721), Mattheson diz que "entende-se por um galant-huomo, alguém firme, hábil, capaz, honesto, valent'uomo (...). ${ }^{7}$ (MATTHESON, 2004 (1721), p.276).

As "três orquestras", como são conhecidos os tratados musicais de Mattheson que antecedem $O$ Mestre-de-Capela Perfeito, são abertamente dedicadas ao público galante. Esta destinação aparece no título de dois deles:

"A ORQUESTRA recém-inaugurada / ou instrução universal sobre / como um Galanthomme pode alcançar uma compreensão perfeita da elevação e da dignidade da nobre música / para formar seu Gout através dela, / entender os Terminos technicos e razoar adequadamente sobre esta admirável ciência". 8 (Hamburgo, 1713)

“A ORQUESTRA protegida (...) em que não apenas o verdadeiro gallant-homme, que não exerce esta profissão, mas também muitos dos próprios músicos podem formar o conceito mais claro e verdadeiro sobre a ciência musical / habilmente depurado da poeira escolástica, / comunicado / e colocado verdadeira e propriamente". 9 (Hamburgo, 1717)

\footnotetext{
${ }^{7}$ Die italiäner verstehen durch einen galant huomo, einen wackern, geschickten, tüchtiger und redlichen Kerl, un valent' uomo (...). Und in solchen, als seinen rechten genuinen Verstande, nehmen wir das Wort auch hier" ${ }^{8}$ Neu-eröffnete ORCHESTRE/oder universelle und gründliche Anleitung/ wie ein Galant-Homme eine volkommenen Begriff von der Hoheit und Würde der edlen Music Erlangen/ seinen Gout darnach formieren/ die Terminos technicos verstehen und geschicklich von dieser vortrefflichen Wissenschafft raisonnieren möge (Hamburg, 1713).

${ }^{9}$ Das Beschützte orchestre (...) Worin nicht nur einem würcklichen gallant-homme, der eben kein Porofessions-Verwandter, sondern auch manchen Musico selbst die alleraufrichtigste und deutlichste Vorstellung musicalischer Wissenschafften/ wie sich dieselbe vom Schulstaub tüchtig gesäubert/ eigentlich und wahrhafftig verhalten/ ertheilet (Hamburg, 1717).
} 
No frontispício de seu último e maior tratado, lê-se, como título completo, “O MESTREDE-CAPELA PERFEITO, / Isto é / Demonstração detalhada / De todas as coisas / Que deve saber, conhecer e levar totalmente em conta aquele que pretende dirigir / Uma Capela / com dignidade e utilidade: / Concebido como ensaio por / MATTHESSON." 10 (Hamburgo, 1739)

Nesta leitura, chama imediatamente atenção a primeira proposta do título: a de descrever o Mestre-de-Capela perfeito, assim como a clara relação com o modelo de perfeição oratória proposta por Cícero e Quintiliano. Como nestas retóricas clássicas, são discutidas questões que envolvem a constituição deste tipo ideal: a possibilidade de se alcançar a perfeição prometida no título, assim como no que constitui esta qualidade; se a perfeição é uma habilidade natural, se pode ser polida pela arte, e, caso isto seja possível, quais conhecimentos (gerais e/ou específicos) contribuem para a construção desta perfeição. Estas ideias serão apresentadas e discutidas abaixo, de modo a fundamentar a compreensão desta obra como emulação de retóricas clássicas.

\section{0 mestre-de-capela perfeito}

O ideal de perfeição moral que prega uma relação estreita entre ética e retórica é de origem grega, e tem como modelo principal a Retórica aristotélica. Contudo, ele também está descrito nos escritos latinos - a obra tardia de Cícero, em especial o De oratore, e a Institutio Oratoria de Quintiliano. Esta questão é, ainda, fundamental para a construção do ideal do cortesão perfeito e, sendo uma questão humanista, foi amplamente discutida nos meios aristocráticos italianos e também no âmbito escolar da Alemanha reformada. Neste sentido, é possível contextualizar a figura Mestre-deCapela perfeito numa longa tradição, da qual Mattheson também é partícipe.

\footnotetext{
10 DER VOLLKOMMENE CAPELLMEISTER / Dass ist / Gründliche Anzeige / Alle derjenigen Sachen / Die einer wissen, können, und vollkomen inne haben muss Der einer Capelle / Mit Ehren und Nutzen vorstehen will: / Zum Versuch entworffen von / MATTHESON (Hamburg, 1739).
} 
O pano de fundo que norteia a preocupação em caracterizar o orador perfeito é o conhecido desprezo de Platão pela arte retórica. Em diálogos como Górgias (1987 (380 a.C), 502e) o filósofo nega que a retórica permita atingir o conhecimento verdadeiro. Por isto, para ele, a retórica representa apenas adulação e engano. ${ }^{11}$ Aristóteles tem opinião diversa da de seu mestre, e credita um valor positivo à retórica, ao afirmar que o bom orador estará necessariamente comprometido com a Verdade. Esta é a posição defendida não apenas por Aristóteles, mas ainda por dois grandes oradores romanos, Cícero e Quintiliano.

Quintiliano é exaltado pelo próprio Lutero, justamente pela preocupação ética que transparece na Institutio Oratoria. Assim como Cícero, Quintiliano também se preocupa em responder às possíveis acusações platônicas contra a retórica. Explicitamente baseado em Catão, Quintiliano apresenta a famosa noção de que o orador perfeito é um vir bonus dicendi peritus: "seja, portanto, o orador que descrevemos, como aquele definido por M. Catão: um homem bom, hábil na fala" (QUINTILIANO, 1998 (c.95), XII,4, p.354) ${ }^{12}$. Ele enfatiza o comprometimento ético do orador: "não apenas afirmo que o orador ideal deve ser um bom homem, mas afirmo ainda que nenhum homem pode ser um orador, a menos que seja um homem bom." (QUINTILIANO, 1998 (c.95), XII,I,4, p.356).13

O ideal do vir bonus teve grande circulação durante os sécs. XVI, XVII e XVIII, reformulado no gênero literário conhecido como institutio aulica, ou escola de corte, que compreende os manuais devotados à descrição do príncipe ou do cortesão perfeitos. No mundo luterano, estes manuais foram utilizados no programa pedagógico

\footnotetext{
11 Para uma discussão mais detalhada sobre Platão e a Retórica, cf. Mc. COY (2010).

12 sit ergo nobis orator, quem constituimus, is, qui a M. Catone finitur, vir bonus dicendi peritus; verum, id quod et ille possuit prius et ipsa natura poetius ac maius est, utique vir bonus (...)."

13 Necque enim tantum id dico, eum, quis it orator virum bonum esse oportere, sed ne futurum quidem oratorem nisi virum bonum.
} 
dos ginásios. ${ }^{14}$ No séc. XVI, este ideal de perfeição passa também a ser discutido nas poéticas musicais. No âmbito italiano, a referencial obra de Gioseffo Zarlino, Institutione Harmoniche (1558), descreve da seguinte maneira o músico perfeito:

\begin{abstract}
Músico é aquele que na Música é perito e que tem a faculdade de julgar, não pelo som, mas pela razão, aquilo que tal ciência contém; e se puser em obra as coisas pertencentes à prática, fará sua ciência ainda mais perfeita, e Músico perfeito poderá chamar-se (...) Não digo, porém, que o compositor e que alguém que se exercita nos instrumentos naturais e artificiais seja, ou deva ser privado deste nome, desde que ele saiba e entenda aquilo que opera e transforme tudo isso com a razão. (...) Se com um só nome devêssemos chama-lo, nós o chamaríamos de Músico Perfeito. (Zarlino, citado por TETTAMANTI, 2010, p.30-31) ${ }^{15}$
\end{abstract}

As ideias de Zarlino são corroboradas pela instituição luterana da musica poetica, sendo propagadas por autores de obras escolares, como Listenius, Fink, Orydrius etc. - cujas definições do musicus poeticus contemplam a figura do músico que domina tanto a musica theorica quanto a composição e a prática instrumental e do canto. Sendo assim, ao ser retomada pelo Der Vollkommene Capellmeister, a transposição do ideal do vir bonus para o âmbito musical já constitui um lugar-comum, antecedido por pelo menos dois séculos de escritos musicais.

Mattheson deixa claro, desde o início de sua maior obra, que o mestre-de-capela perfeito não descreve uma pessoa subjetiva, mas sim um tipo ideal, que, em essência, é uma emulação do vir bonus de Catão. Com efeito, o prefácio de $O$ Mestre-de-Capela

\footnotetext{
${ }^{14}$ Entre as obras mais difundidas na Alemanha, encontram-se traduções de Alberto Guevara, Baltazar Gracián, Giovanni della Casa e Baldassare Castiglione (cf. BARNES, 2002, p.138-149).

${ }^{15}$ Musico esser colui, che na musica è perito, \& hà faculta di giudicare, non per il suono; ma per ragione quello, que intal scienza si contient. Il quale se alle cose appartinenti ala prattica dará opera, farà la sua scienza più perfetta. \& Musico perfetto si portrà chiamare. (...). Non dico però, che'l compositore, \& alcuno che esserciti li naturali, o artificiali istrumenti sai, o debba esser privo di questo nome, pur che egli sappia \& intenda quello, che operi; \& del tutto renda conv enevol ragione (...). Se com um solo nome lo dovessimo chiamare, lo chameremo Musico Perfetto. (trad. de Giulia Tettamanti).
} 
Perfeito principia com uma explicação do título. Ele assemelha sua obra a outras emulações do vir bonus, com destaque para a escola de corte L'Ambassadeur et ses fonctions, (Haia,1682) de Abraham de Wicquefort. Ele afirma, ainda, que este tipo perfeito aparece ainda em outros contextos: o diplomata, o general, o sábio estóico (ao estilo de Sêneca). Para Mattheson (1992 (1739), p.9), todos estes autores "descreveram coisas e pessoas segundo o conceito que possuíam de perfeição". ${ }^{16}$ Estes exemplos justificam a preocupação de Mattheson em redigir uma obra dedicada ao mestre-de-capela perfeito.

Cícero e Quintiliano não descartam a possibilidade de o orador perfeito vir a existir, ainda que isto jamais tenha ocorrido. Mattheson, operando na chave cristã, nega esta possibilidade, uma vez que, para ele, a perfeição é exclusivamente atributo divino. Para ele, o termo perfeição só pode ser aplicado em comparação com outras coisas da mesma espécie ou em oposição à imperfeição que nelas aparece: "honesto, por exemplo, não descreve o homem absolutamente honesto, mas aquele que age de maneira mais íntegra do que as pessoas comuns". 0 mestrede-capela perfeito, para Mattheson, é um tipo galante.

Uma vez definido o galant-homme como destinatário do Der Vollkommene Capellmeister, fica clara a preocupação ética que subjaz ao tratado, apresentada já no título: "o mestre-de-capela perfeito, contendo descrição das coisas necessárias àquele que deseja conduzir uma capela com dignidade e utilidade." Em diversos pontos de sua extensa obra teórica musical, Mattheson manifesta seu direcionamento ético. Na Orquestra Investigativa, ele afirma:

\begin{abstract}
Aristides Quintiliano, quando discorre sobre a finalidade da música, mostra de certa forma seu sentido. Ele não é contrário a todo prazer que se deriva da música, mas afirma que este prazer não é a verdadeira intenção da música. 0 prazer é, por acaso, uma recreação do espírito.
\end{abstract}

\footnotetext{
16 In solcher guten Absicht haben auch andre, und auch zwar löbliche Werke dergleichen Auffschrifft geführet (...) Seneca gestehet von seinem stoischen Weisen, Cicero von seinem vollkommenen Redner, andre von andern Vollkommenheiten, , das dergleichen noch niemals in der Welt anzutreffen gewesen; dennoch haben diese Verfasser (...) ihre Sachen und Perssonen nach den vollkommensten Bebriff, den sie davon gehabt, vorgestellet.
} 
Mas seu sentido verdadeiro é a utilidade e a compreensão da Virtude.

(MATTHESON, 2004 (1721), p.174|) ${ }^{17}$

A preocupação com os efeitos morais da música é mais detalhadamente descrita por Mattheson numa coleção de escritos intitulada "O patriota musical, que compartilha suas observações detalhadas sobre as harmonias espirituais e mundanas, e sobre aquilo que diretamente delas depende, com variedade agradável, para que seja incentivada em todo o leitor a edificação moral” 18, 1728. Na Décima Primeira Consideração desta obra, Mattheson afirma:

\begin{abstract}
Basta recordar àquele a quem parece estranho que a música se refira a estas coisas, que esta ciência é uma perfeita imagem da moderação e, consequentemente, também da tolerância, e de todas as virtudes. Aquele que, através da música, não aprende a virtude, não é digno de que sua garganta seja apta ao cantar ou seus dedos, ao tocar. ${ }^{19}$ (MATTHESON, 1728, p.89)
\end{abstract}

Dentre as composições musicais de Mattheson, chama atenção a coleção de sonatas para violino ou traverso acompanhadas de baixo-contínuo, intitulada Der Brauchbare Virtuoso ("O virtuose útil”), de 1727. No prefácio destas peças, Mattheson apresenta a etimologia do termo italiano virtuose, do latim virtus. Ele questiona se este conceito se refere à virtus intelectualis, ou seja, à força do juízo, ou à virtus moralis, à retidão nos

\footnotetext{
${ }^{17}$ Aristides Quintilianus, wenn er von dem Endzweck der Music redet, gibt seinen Sinn ungefehr also zu erkennen: Est ist weder alle Lust, die man aus der Music schöpfet, zu tadeln, noch auch diese Lust die eigentliche Absicht bey der Music. Die Lust ist zwar zufälliger Weise eine Gemüths-Ergötzung. Aber der recht vorgesetzte Zweck ist der Nutz zur Ergreiffung der Tugend." In: Die Forschende Orchestre, p.174 p.174.

${ }^{18}$ Der Musikalische Patriot, welcher seine gründliche Betrachtungen, über Geist- und Weltl.

Harrmonien, samt dem, was durchgehends davon abhänget, In angenehmer Abwechselung zu solchem Ende mittheilet, Daß GOttes Ehre, das gemeine Beste, und eines jeden Lesers besondere Erbauung dadurch befördert werde. Ans Licht gestellet von Mattheson (Hamburg, 1728).

${ }^{19}$ Dem es frembd scheinen solte, dass sich auch die Musik auf diese Dinge deuten lasse, der beliebe nur zu erwegen, dass diese Wissenschaft ein rechtes Ebenbild der Mässigkeit, und folglich auch der Geduld, ja aller Tugenden ist. Wer keine Tugend aus der Musik lernet, der ist nich werth, dass sein Hals zum singen, noch seine Finger zum spielen, geschickt seyn sollen.
} 
costumes. 0 virtuose, ou seja, aquele que se destaca por uma excelência técnica, deve possuir ambas as qualidades, intelectual e moral.

\begin{abstract}
Os virtuoses que possuem apenas a aptidão intelectual não podem ser entendidos como úteis, já que, sendo esta uma qualidade eminentemente moral, depende da ação. Por isto, estes artistas não podem ser considerados virtuoses no sentido estrito do termo: "é possível ser um virtuose (teórico), mas no âmbito geral, ser inútil e vergonhoso (...). Os músicos teóricos, se não souberem agir, serão inúteis ou mesmo nocivos. Os músicos práticos, por outro lado, não sabem necessariamente o que sejam os hábitos (Mores), e, por isso, podem possuir vícios como a gula, a bebida, a falta de vergonha, o bafo de tabaco, a falta de gentileza, a falta de pureza, a falta de Deus, o hábito de praguejar etc. (MATTHESON, 1720, p.3) ${ }^{20}$
\end{abstract}

Consequentemente, somente poderá ser chamado virtuose, no verdadeiro sentido da palavra, aquele que unir bons hábitos à excelência prática. Mattheson retoma uma leitura obrigatória das escolas luteranas, o De civilitate morum puerilium (1530) de Erasmo de Rotterdam, ao afirmar que um virtuoso, por mais hábil que seja, deve levar os bons hábitos (Sitten) para o íntimo de sua alma" (MATTHESON, 1720, p.2). É possível perceber, em todos os escritos de Mattheson, a preocupação em vincular a música à edificação moral. É evidente que esta preocupação está fundamentada na concepção latina do vir bonus e em suas emulações humanistas, em especial o ideal francês do galant homme, considerando a enorme circulação destas ideias na Alemanha reformada.

\footnotetext{
${ }^{20}$ Die Virtus intellectualis kan demnach bey einem Subjecto gänzlich oder zum Theil von der moral entblösset seyn und is mancher zwar ein Virtuoso, aber gemeiniglich ein schändlicher und unbrauchbarer. (...)Derowegen muss man ihnen [den Virtuosen] nur teutsch sagen dass ihren vornehmsten Sitten in in folgenden Stenen bestehen: fressen, Saufen, Unverschämtheit, Tobackgestank, Unhöfflichkeit, Unreinlichkeit, Gottlosigkeit, Schweren, fluchten, Verläumden, Schelten, grstige Reden und Thaten, falscheit, Vergendung, Faulheit, Müssigang und dergleichen.
} 


\section{Requisitos para a perfeição}

Dentre os lugares comuns que Mattheson retira de retóricas latinas e utiliza na definição de seu mestre-de-capela, serão abordados neste artigo aqueles que se referem à ideia de perfeição: a oposição entre arte e natureza e a consequente definição da música (assim como da oratória) como arte, além da ideia de que o orador não deve restringir seus conhecimentos apenas às técnicas específicas, devendo, antes, ser possuidor de conhecimento universal.

No que diz respeito à oposição entre arte e natureza, além da definição dos termos, surgem duas questões básicas: é possível prescindir de alguma das duas, ou são ambas essenciais na formação do bom orador? em caso de as duas serem fundamentais, qual delas é mais importante? Cícero entende por natureza as habilidades inatas do orador. No que concerne à disposição física, é importante que ele tenha língua ágil, boa capacidade pulmonar, voz sonora e boa aparência. Além disto, ele deve possuir engenho, ou rapidez de espírito: "é mister que o orador se mostre agudo na invenção, rico na amplificação e no ornato, firme e tenaz na memória" (CÍCERO, 1942 (55 a.C), I,25,113-114, p.80-81).21 No decorrer de seu livro, Mattheson também menciona, como qualidades naturais do mestre-de-capela perfeito, boa voz, engenho e entusiasmo.

A arte, de maneira diversa, constitui a categoria das habilidades passíveis de ensino e de exposição sistemática. No livro I do De oratore, Crasso, ao responder uma questão de Antonio, afirma que arte é, num sentido geral, uma habilidade que se define por princípios claros, bem conhecidos, independentes de toda opinião e sujeita à ciência. Contudo, num sentido mais estrito, ele chama arte ao conjunto de observações feitas na prática por homens discretos e entendidos, escritas, e, portanto, divididas e classificadas. A esta segunda categoria pertence a arte do bem dizer (CÍCERO, 1942 (55 a.C.), I,2,8, p.8-9).

\footnotetext{
${ }^{21}$ Nam et animi atque ingenii celeres quidam motus esse debent, qui et ad excogitandum acuti, et ad explicandum ornandumque sint uberes, et ad memoriam firmi atque diuturni.
} 
Heinrich Lausberg (1995 (1949), §28, p.85) define arte como "uma faculdade possuída por um indivíduo e comprovada na prática, com o fim de levar a cabo, com sucesso e repetidas vezes, empresas importantes". A arte visa à perfeição, o que justifica as inúmeras descrições do Orador, do Cortesão ou do Músico perfeitos. Lausberg afirma, ainda, que, como objeto de ensino, a arte é "um sistema constituído pela experiência que o mestre adquiriu na sua própria criação artística e no ensino de regras doutrinárias (...) ordenadas consequentemente, com o fim de levar a cabo, com sucesso, a realização artística" (CÍCERO, 1942 (55 a.C.), §28, p.86).

Neste sentido, a retórica pode ser entendida como uma arte. Em uma famosa definição de Quintiliano, a retórica constitui "a arte do bem dizer" (ars bene dicendi), e constitui o assunto das preceptivas oratórias.

Nas preceptivas latinas, lemos que tanto arte quanto natureza concorrem para a formação do orador perfeito. Contudo, a primeira, por se tratar de uma disposição inata, não é ensinável. Para estar em condições de alcançar a perfeição, é preciso conhecer a arte, ou doutrina, assunto das preceptivas retóricas.

Na Institutio Oratoria, Quintiliano nos diz:

Bem sei que ainda se costuma questionar se é a natureza que mais contribui para a eloquência, ou se é a doutrina (arte). Na verdade isso nada tem que ver com o propósito da nossa obra, pois um orador consumado não pode ser constituído senão a partir de ambas (...) Por que se se separa uma da outra, a natureza, mesmo sem a doutrina, 
valerá muito, mas a doutrina nada poderá sem a natureza. (QUINTILIANO, 1998 (c. 95), II,19,1-2, p.147) 22

Em seu discurso sobre o poeta Árquias, Cícero também discorre sobre esta tópica, e diz que

Frequentemente, mais vezes importaram para o louvor da virtude a
natureza sem doutrina (arte) do que a doutrina sem a natureza. E
posso ainda asseverar o seguinte: quando a distintos e excelentes dons
naturais se soma uma certa instrução e doutrina, não sei que possa
existir de mais preclaro e singular. (CÍCERO, 1986 (62 a.C.), VII,15,
p.45)

Horácio também versa sobre este assunto em sua epístola dedicada aos Pisões (Arte Poética): “tem-se perguntado se um poema se torna digno de louvor pela natureza ou pela arte. Eu não vejo de que serve o trabalho sem uma veia fértil, nem de que serve o engenho rude; assim uma coisa reclama o auxílio da outra e conspiram amigavelmente (HORACIO, 1984 (18 a.C.), 408-411, p.23 e 36). ${ }^{24}$

Mattheson emula seus antecessores latinos, ao discorrer sobre este lugar-comum, embora no tratado não haja uma descrição genérica sobre o assunto e sim diversas referências a eles, por exemplo, no capítulo sobre a inventio :

Muitos possuem a capacidade de encontrar milhares de boas ideias a partir do espírito livre, por possuírem uma imaginação forte (...).

\footnotetext{
22 Scio quaeri etiam naturane plus ad eloquentiam conferat an doctrina. Quod ad propositum quidem operis nostri nihil pertinet (neque enim consummatus orator nisi ex utroque fieri potest)

[...] Nam si parti utrilibet omnino alteram detrahas, natura etiam sine doctrina multum ualebit, doctrina nulla esse sine natura poterit.

${ }^{23}$ Saepius ad laudem atque uirtutem naturam sine doctrina quam sine natura ualuisse doctrinam! Atque idem ego hoc contendo: cum ad naturam eximiam et ilustrem accesserit ratio quaedam conformatioque doctrinae, tum illud nescio quid praeclarum ac singulare solere exsistere. Cf. ainda I,79,91 e 113.

${ }^{24}$ Natura fieret laudabile carmen na arte, quaesitum est; ergo nec studium sine divite vene ne rude quid prosit video ingenium; alterius sic altera poscit opem res et coniurat amice.
} 
Outros compõem incomparavelmente bem, mas não têm a menor capacidade para obter pensamentos de maneira imediata, sem raciocínio. (...) Aqueles que encontram seus pensamentos antes com o fantasiar são verdadeiramente os melhores. Contudo, (...) a natureza (...) e a técnica são extremamente necessárias e requeridas para o compositor e para o mestre-de-capela. (MATTHESON, 1991 (1739), II,2,50-61, p.107-108). ${ }^{25}$

Para Cícero, a arte apenas pode tornar melhor o que é bom por natureza, ou aguçar e corrigir de algum modo o que não é perfeito. 0 mesmo vale para Mattheson. Para ele, o mestre-de-capela perfeito deve ser "alegre, bem humorado, inabalável, trabalhador, ativo e ordeiro. A preguiça, o excesso de sono e a vida voluptuosa assim como a impaciência e a ansiedade, devem ser odiados." (MATTHESON, 1991 (1739), II,2,55, p.107). ${ }^{26}$ Ele afirma ainda a necessidade do trabalho, da disciplina, e do estudo constante para alcançar a perfeição (MATTHESON, 1991 (1739), II,11,58, p.107), fazendo, com isto, louvor à arte.

No que tange à questão do conhecimento, retóricas latinas afirmam que o orador perfeito deve ser versado em diversas áreas do saber, e, deste modo, sem erudição, não é possível se alcançar a perfeição. Para Cícero, a eloquência é possível e desejável, contanto que o orador não discorra sobre todos os assuntos sem de fato conhecer nenhum. Neste referencial diálogo, Cícero, na pessoa de Crasso, afirma que a eloquência não se restringe apenas, como sugere seu interlocutor Quinto, a um "certo engenho e exercício" (CÍCERO, 1942 (55 a.C.), I,5,17, p.14-15). Pelo contrário, ela exige o concurso de todas as demais artes que os homens cultos possuem: "o orador perfeito

\footnotetext{
${ }^{25}$ Viele besitzen die Gabe, aus freiem Geiste und stehenden Fusses tausenderley gute Einfälle hervor zu brinetn (...). Andere haben nicht das geringste Vermögen, etwas aus dem Stegereiffe, ohne Bedenckzeit, zu vollstrecken. Diejenigen (...) so ihre Gedancken erst mit Fantasiren entdecken (...) sind wircklich die allerbesten. (...) Nehmlich: das Naturell, die Lust und der Fleiss [sind] einem Componisten und Vorgesetzten auf unzertrennliche Art höchst-nöthig und erforderlich.

${ }^{26}$ [Es ist erfordert], dass ein Componist und Vorsteher der Musik eines muntern, auferäumten, unverdrossenen, arbeitsamen und thätigen Wesens sey; doch auch ordentlich dabey: woran es offt bey den allerlebhafftesten fehlet. Der Müssigang muss, gehasset werden.
} 
requer a agudeza dos dialéticos, as sentenças dos filósofos, o estilo dos poetas, a memória dos jurisconsultos, a voz dos trágicos e os gestos dos melhores atores". Ninguém, na opinião de Crasso, poderá ser um orador perfeito se não alcançar uma instrução universal nas ciências e nas artes" Sendo assim, a sabedoria é geradora do poder oratório. (CÍCERO, 1942 (55 a.C.), I,14,63, p.46-47) 27.

Cícero inclui, em sua proposta de erudição universal, o conhecimento das leis, da Antiguidade e do direito civil. Para Quintiliano (1998 (c. 95), I,1,4-6, p.20-23), o orador deve, ainda, ser versado na filosofia, sobretudo moral, mas também natural, e na lógica. Além destas, ele deve conhecer a retórica, a gramática, a música, a geometria e astronomia - conhecimentos que futuramente virão a constituir as artes liberales.

Mattheson, igualmente, dedica um capítulo inteiro de seu importante tratado às qualidades extra-musicais do compositor. Ele afirma que, em primeiro lugar,

\begin{abstract}
um compositor não destacar-se-á em sua arte sem erudição. Um pintor pode ser artista, mas se não for historiador, fará um quadro que, embora tecnicamente perfeito, não expressará os movimentos de alma condizentes com o conteúdo da história. 0 mesmo se subentende do compositor: seu trabalho pode ser obra de mestre dedicado, mas se lhe falta erudição, não saberá levar em consideração a natureza de seu texto, como acontece com o pintor e as paixões de seu quadro. Beer acrescenta: uma coisa é a destreza técnica no pincel, outra, a habilidade na expressão. (1991 (1739), II,2,4, p.100)28
\end{abstract}

\footnotetext{
${ }^{27}$ Illud verius, neque quemquam in eo disertiun esse posse, quod nesciat; neque, si id optime sciat, ignarusque sit faciundae ac ohendae orationis, diserte id ipsum posse, de quo sciat, dicere.

${ }^{28}$ Ein ungenannter Französischer Schriffteller meldet ausdrücklich: ein Componist werde nimmer in seiner Kunst hervorragen, falls er keine Gelehrsamkeit besitze. Ein Mahler kann wol ein Künstler seyn; ist er aber kein Historicus, so wird er zwar ein künstliches Bild, doch nicht die Gemüths-Bewegungen, welche es, nach dem Inhalt der Geschichte, haben sollte, ausdrücken. Ein gleiches verstehe man von einem Componisten; seine Arbeit kan endlich das Stück eines fleissigen Meisters heissen; weil es ihm aber an der Gelehrsamkeit mangelt, hat er die Natur des Textes, wie der Mahler die Leidenschafften seines Bildes, nicht in Acht nehmen Können. Beer setzt hinzu: Ein anders sey künstlich im Pimsel; ein aders künstlich im Ausdruk. Und darin hat er kein Unrecht.
} 
Cícero (1942 (55 a.C.), II,6, p.200-201) conclui, afirmando que a arte, ou seja, a habilidade técnica, jamais poderá ser posta plenamente em prática sem 0 conhecimento das matérias. Mattheson, de maneira semelhante, enfatiza que o músico que não vai além de suas ferramentas específicas é um pedante (MATTHESON, 1991 (1739), II,2,31). Para ele, o músico deve ser poeta e até mesmo profeta (MATTHESON, 1991 (1739), II,2,9). Vale lembrar que a música é uma das disciplinas mais importantes no currículo escolar reformado.

Para Cícero, é fundamental que o orador possua erudição no mais alto grau: "se nas demais artes basta uma tolerável mediania, no orador é necessário que estejam reunidas em grau máximo todas as qualidades" (CÍCERO, 1942 (55 a. C.), I,28, 128)29. Mattheson ecoa Cícero já na epígrafe do Mestre-de-Capela Perfeito, ao citar um adágio de Erasmo: "pleraque res sunt, qus si facias acriter, plurimus conducunt; sin ignaviter, officiunt. Velut ea, quae mediocritatem non recipiunt, quod genus est Musica Poeticaque. Sunt rursus quaedam, quae degustasse sit satis." ("quantas atividades são admiráveis se a elas nos dedicarmos integralmente, e prejudiciais nos aplicarmos de maneira morna. Há coisas que não aceitam a mediania; entre estas, encontram-se a música e a poesia. Há coisas que devem ser degustadas plenamente.") (MATTHESON, 1991 (1732), p.9) ${ }^{30}$.

Para Cícero e Quintiliano, a erudição geral antecede os conhecimentos específicos, embora ambos sejam indissociáveis. Conhecimentos que pertencem tanto ao âmbito

\footnotetext{
${ }^{29}$ Quae enim singularum rerum artifices singula si mediocriter adepti sunt, probantur, ea, nisi omnia siunma sunt in oratore, probari non possunt.

$30 \mathrm{O}$ adágio de Erasmo diz: Oportet testudinis carnes aut edere aut non edere (Quando se lhe oferecem carne de tartaruga, é preciso comer ou não comer). Na explicação, Erasmo diz: come ou não come a tua tartaruga: é preciso escolher, assim diz um iâmbico proverbial dirigido àqueles que, decidindo realizar uma tarefa, a fazem vagarosamente, nunca a terminando ou dela desistindo. (...). Diz-se que a carne de tartaruga, comida em quantidades moderadas, é causadora de constipação, que é desfeita quando a mesma é consumida em grandes quantidades (...). É uma maneira de dizer: decida; vá a guerra ou não vá; estude ou não estude. Lembre-se de quantas atividades são admiráveis se nos dedicamos integralmente a elas, e são prejudiciais se nos dedicamos a elas de maneira morna, já que estas, como a música e a poesia, não admitem a mediocridade (ERASMO, 2001, X,10,60, p.130).
} 
geral quanto ao específico são, para Cícero, a escolha correta das palavras, o conhecimento das paixões humanas, a amenidade e graça no discurso, a rapidez e oportunidade no responder e no atacar, a beleza e agudeza no estilo e a urbanidade. São, ainda, necessários para o orador os conhecimentos próprios do ator: a actio (experiência acerca dos movimentos do corpo, dos gestos, dos semblantes e das inflexões da voz) e a memoria.

Mattheson também especifica alguns conhecimentos gerais necessários para o músico perfeito: conhecimento dos aspectos matemáticos dos temperamentos e da harmonia; conhecimento da língua grega e latina, suficientes para entender escritos sobre música, além da da língua francesa e, sobretudo, italiana, línguas próprias do galant-homme. 0 mestre-de-capela deve também ser versado na melopoesia, ou seja, a poesia adequada à música; sem o conhecimento desta, incorrerá nos vícios da monotonia, das ideias repetidas e do excesso de dissonâncias. 0 músico perfeito deve saber dominar as paixões de sua audiência, e para isto, Mattheson descreve-as no capítulo 3 da primeira parte de $O$ Mestre-de-Capela Perfeito. Por fim, ele deve cantar e tocar bem um instrumento, preferencialmente de teclado, e dominar ou ao menos conhecer os outros instrumentos. Por fim, o músico ideal deve dominar o estilo de composição italiano, embora não seja essencial ter ido àquele país para aprendê-lo (MATTHESON, 1991 (1732), II,2,1-46, p.99-106).

Um traço tipicamente luterano da obra literária Mattheson é seu interesse pelo estudo da música sob a perspectiva ética e teológica. Esta preocupação é característica de escritos musicais humanistas, como a referencial descrição do músico perfeito por Gioseffo Zarlino, em seu Istitutzione Harmoniche, e um assunto sempre presente nas poéticas musicais produzidas no âmbito luterano. ${ }^{31}$ Ela também aparece no Der Vollkommene Capellmeister. No fim da vida, Mattheson se aprofunda nos aspectos teológicos da música. ${ }^{32}$

\footnotetext{
${ }^{31}$ Mais informações sobre a ideia do músico-cortesão em PORTO, Delphim (2013, p.11-25).

32 Especialmente em um escrito não publicado, intitulado "Behauptung der himmlischen Musik aus den Gründen der Vernunft, Kirchen-Lehre und heiligen Schrift” [Defesa da música celeste baseada
} 


\section{5 - Conclusão}

Neste texto, ficou claro como a vida de Mattheson, publicada na Grundlage einer Ehrenpforte pode ser lida, a partir da perspectiva retórica, não como narração subjetiva, mas, sob a perspectiva retórica, como escrito codificado, sujeito a regras preceituadas para diferentes gêneros literários. 0 mesmo pode ser dito a respeito da descrição que Mattheson apresenta do músico-orador perfeito em Der vollkommene Capellmeister. Neste último e referencial escrito, as descrições do músico-orador perfeito emulam manuais latinos de eloquência.

A partir desta chave de leitura, o objetivo do presente texto foi o de evidenciar e discutir alguns dos lugares-comuns aplicados por Mattheson à descrição do mestre-de-capela perfeito. Estes lugares já figuram em preceptivas clássicas, integram os escritos humanistas e reaparecem nas poéticas musicais. A utilização destes lugares é possível pois Mattheson parte do pressuposto que a música é comparável ao discurso verbal, o que permite a ele afirmar que os princípios da oratória sejam também adequados à música.

O primeiro dentre os lugares comuns apresentados neste artigo é constituído pelo próprio título, que promete descrever o ideal de perfeição moral do mestre-de-capela, nos moldes do orador idealizado por Cícero e Quintiliano. A questão inicial, a capacidade humana para atingir a perfeição, não é passível de resposta taxativa, mas serve para abrir a discussão para as qualidades desejáveis ao músico-cortesão.

A segunda questão, que avalia a importância da contribuição da natureza e da arte para a constituição do orador perfeito, também dá margem a muitas opiniões, mas constitui, igualmente, um excelente artifício para justificar a existência do material que o leitor tem em suas mãos: um manual que ensina os preceitos da arte musical. Mattheson não

na razão, na doutrina da Igreja e na Escritura sagrada"]. Para mais informações, cf. CANNON (1968) p.101 e p.207. 
se detém explicitamente na dicotomia arte-natureza, mas ela é evidente em várias passagens de sua obra.

Mattheson, como seus antecessores latinos, enfatiza a importância dos conhecimentos gerais para a formação do músico-orador perfeito. Diversos destes conhecimentos são comuns tanto ao orador quanto ao mestre-de-capela: conhecimento de outras ciências e artes, domínio sobre as paixões, agudeza etc. Outros são próprios de cada arte, seja a música, seja a oratória. Contudo, a despeito destas diferenças, é possível notar que todos afirmam que o artista perfeito deve extrapolar os conhecimentos técnicos específicos. Esta asserção é recorrente em escritos sobre oratória, assim como nos manuais humanistas de cortesania.

A discussão do uso que Mattheson faz dos lugares-comuns relativos à perfeição oratória-musical mostra de maneira clara como o autor se ampara na tradição retórica, recuperada por humanistas italianos e do mundo luterano, para produzir a mais importante obra da instituição da Musica Poetica, obra que ainda hoje segue sendo a mais profunda transposição dos princípios retóricos para a linguagem musical.

\section{Referências}

1. BARNES, Wilfried. (2002) Barockrhetorik. Tübingen: Max Niemeyer.

2. BLUTEAU, Raphael.(1712) “Galante”. In: Vocabulário Portuguez e Latino (Coimbra,1712-1728). Disponível em: http://www.brasiliana.usp.br/ptbr/dicionario/edicao/1. Acesso em 3 ago. 2014.

3. CANNON, Beekman C. (1968) Johann Mattheson. Spectator in Music. Yale: Archon.

4. CÍCERO (1942). De Oratore (c.55a.C.). Harvard: Loeb.

5. CÍCERO (1986). Em defesa do Poeta Árquias (Pro Archia Poeta Oratio, 62 a.C.). Mem Martins: Inquérito (trad. Maria Isabel Rebelo Gonçalves).

6. ERASMO de Rotterdam. (2001) The Adages of Erasmus. Toronto: University of Toronto Press (trad. William Barker). 
7. HORÁCIO. (18 a.C.) Arte Poética. São Paulo: Musa (trad. Dante Tringali).

8. LAUSBERG, Heinrich. (1995) Elementos de Retórica Literária. 3a edição. Lisboa: Gulbenkian (1aㅡ ed. 1949).

9. LUCAS, Mônica. “Emulação de Retóricas Clássicas em Preceptivas da Musica Poetica". Opus. São Paulo: ANPPOM. v.20 n.1, p.71-94. Disponível em http://www.anppom.com.br/opus/data/issues/archive/20.1/files/OPUS 201 lucas. pdf. Acesso em 9 dez. 2014.

10. MATTHESON, Johann. (2004) Das Beschützte Orchestre (Hamburg, 1717). Laaber: Laaber Verlag.

11. . (2004) Das Forschende Orchestre (Hamburg, 1721). Laaber: Laaber Verlag.

12. (2004) Das Neu-eröffnete Orchestre (Hamburg, 1713). Laaber: Laaber Verlag.

13. (1720) Der Brauchbare Virtuoso. Disponível em http://erato.uvt.nl/files/imglnks/usimg/d/d4/IMSLP18784-PMLP44426Matthesson Der Brauchbare Virtuoso.pdf. Acesso em 4 out. 2012.

14.___ (1728) Der Musikalische Patriot. Disponível em http://archive.org/details/DerMusicalischePatriot1728. Acesso em 10 out. 2012.

15. Bärenreiter.

16. (1740) Grundlage einer Ehrenpforte. Disponível em: http://imslp.org/wiki/Grundlage einer Ehren-Pforte \%28Mattheson, Johann\%29. Acesso em 5 nov. 2012.

17. Mc COY, Marina. (2010) Platão e a Retórica de Filósofos e Sofistas. São Paulo: Madras.

18. MORROW, Mary Sue. (1997) German Music Criticism in the late Eighteenth Century. Cambridge: Cambridge University Press.

19. PLATÃO. (1987) Górgias (c. 380 a.C.). Madrid: Gredos.

20. PORTO, Delphim. (2013) Girolamo Diruta: Il Transilvano - diálogo sobre a maneira correta de tocar órgão e instrumentos de teclado. Um estudo sistemático do tratado e da música em princípios do séc. XVII. São Paulo: Escola de Comunicações e Artes da Universidade de São Paulo (Dissertação de Mestrado em Música). 
21. QUINTILIANO, Marcus Fabius. (1998) Institutio Oratoria (c. 95 a.C.). Harvard: Loeb

22. (2005) Ciência do bem dizer. A concepção de retórica de Quintiliano em Institutio Oratoria, II, 11-21.São Paulo, Humanitas (tradução: Maria Beatriz Ávila Vasconcelos).

23. TETTAMANTI, Giulia. (2010) Silvestro Ganassi: obra intitulada Fontegara: um estudo sistemático do tratado abordando aspectos da flauta-doce e da música instrumental do século XVI. Campinas: Instituto de Artes da Universidade Estadual de Campinas (Dissertação de Mestrado em Música).

24. VORBAUM, Reinhold. (1863) Evangelische Schulordnungen, vol. II: Die evangelischen Schulordnungen des siebzehnten Jahrhunderts. Gütersloh: Bertelsmann.

Nota sobre a autora

Mônica Lucas graduou-se em música na Universidade de São Paulo e especializou-se na interpretação da música antiga no Real Conservatório de Haia (Holanda), obtendo diplomas em flauta-doce e em clarinetes históricos. Coordena desde 2001 o Conjunto de Música Antiga na ECA-USP. Seu trabalho como pesquisadora, financiado desde 2002 pela FAPESP (doutorado, pós-doutorado e auxílio à pesquisa), envolve o estudo da instituição da Musica Poetica. É autora de "Humor e Agudeza em Haydn: os Quartetos de Cordas op. 33" (Anna Blume/FAPESP, 2008). Desde 2013, é Chefe do Departamento de Música da ECA-USP, onde também atua como docente, sendo responsável pelas disciplinas "História da Música", "História da Ópera" e "Introdução à Retórica da Música Setecentista". 